\title{
ATTITUDE OF NURSES TOWARDS CARE OF ELDERLY PEOPLE IN TEACHING HOSPITALS OF KATHMANDU VALLEY.
}

\author{
Khagi $B R^{1^{*}}$, Maharjan $S A^{2}$, Bajracharya $S L^{2}$, Upadhyay $R^{4}$, Shrestha $K B^{5}$
}

\begin{abstract}
Affiliation
1. Assistant Professor, Department of Nursing, Patan academy of health sciences (PAHS), School of nursing and midwifery, Lalitpur, Nepal

2. Associate Professor, Department of Nursing, Patan academy of health sciences (PAHS), School of nursing and midwifery, Lalitpur, Nepal

3. Associate Professor, Department of Nursing, Patan academy of health sciences (PAHS), School of nursing and midwifery, Lalitpur, Nepal

4. Teaching Assistant, Department of Psychiatric Nursing, Maharajgunj Nursing Campus, Maharajgunj, Nepal

5. Data Analytic Expert, Innovative Solution, Lalitpur, Nepal
\end{abstract}

\section{ARTICLE INFO}

Received : 04 May, 2020

Accepted : 15 August, 2020

Published : 05 October, 2020

(C) Authors retain copyright and grant the journal right of first publication with the work simultaneously licensed under Creative Commons Attribution License CC - BY 4.0 that allows others to share the work with an acknowledgment of the work's authorship and initial publication in this journal.

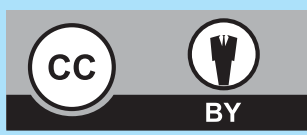

ORA 175

DOI: https://doi.org/10.3126/bjhs.v5i2.31375

\section{* Corresponding Author \\ Ms. Bina Rana Khagi \\ Assistant Professor \\ Department of Nursing}

Patan Academy of Health Sciences (PAHS)

School of Nursing and Midwifery, Lalitpur, Nepal

Email ID: binakhagi@gmail.com

ORCID ID: https://orcid.org/0000-0002-9225-5371

\section{Citation}

Khagi BR, Maharjan SA, Bajracharya SL, Upadhyay R, Shrestha KB. Attitude of Nurses Towards Care of Elderly People in Teaching Hospitals of Kathmandu Valley. BJHS 2020;5(2)12: 1022-1026.

\section{ABSTRACT}

\section{Introduction}

Globally, the numbers of elderly population are increasing which is one of the challenges for nurses in health care setting. Nurses' attitude towards elderly people is associated to quality of care they provide.

\section{Objective}

To identify attitude of nurses towards care of elderly people in teaching hospitals of Kathmandu valley.

\section{Methodology}

A cross sectional research design was used to identify attitude of nurses towards care of elderly people. Proportionate stratified random sampling technique was used to select 450 nurses. Ethical approval was taken from Institutional Review Board of Nepal Health Research Council. Data collection was done from $17^{\text {th }}$ April 2017 to $16^{\text {th }}$ April 2018 by using self-administrative questionnaire on socio-demographic characteristics and Multi-factorial Attitude Questionnaires (MAQ) to measure attitude. Data analysis was done using descriptive and inferential statistics.

\section{Results}

The study revealed that $55.3 \%$ of respondents had negative attitude and $44.7 \%$ had positive attitude towards care of elderly people. There was significant association between age, marital status, studied geriatric nursing and work experiences in nursing with attitudes of nurses. However, there is no association found of ethnicity, religion, type of family, living with elderly, education and currently working with elderly with attitudes of nurses.

\section{Conclusion}

From these findings, it is concluded that more than half of the nurses had negative attitude towards care of elderly. Gerontological nursing course plays significant role in the attitude of nurses. Therefore, it should be given continuity in all level of nursing education for providing quality care of elderly people.

\section{KEYWORDS}

Attitude, elderly, nurses, care, teaching hospital 


\section{INTRODUCTION}

Old age is a natural aspect of life, a process that begins from the time of birth. As the age advances, there is decline in physical function of the elderly which leads to loss of independency and increase susceptibility to health problem. ${ }^{1}$ The number of people in the world aged 60 and above is expected to grow by 56 percent, from 901 million to 1.4 billion between 2015 and 2030, and by 2050 the global figure of older people is projected to be more than double in its size in 2015; reaching nearly 2.1 billion and $80 \%$ of them will be residing in developing countries where the ageing population is growing faster than in the developed regions. ${ }^{2}$

In Nepal, the elderly population accounts for about 8.1 percent of the total population. ${ }^{3}$ The elderly population aged 60 and above, has increased at an annual growth rate of $3.39 \%$ while the general population has increased at an annual growth rate of $1.35 \%$ in the period between 1981 and $2011 .{ }^{4}$ Due to this growing population of elderly, there will be a greater demand for nursing care because elder people have more hospitalization days and use the largest portion of health services. ${ }^{5}$

Attitude is the expression of one's beliefs, feelings, and experiences about an object or concept, and they are reflected through cognition and affection and influence one's behavior. It is a disposition to respond favorably or unfavorably to an object, person, or event. ${ }^{6} \mathrm{~A}$ negative attitude towards ageing is associated to low quality of care thereby affecting quality of life of elderly people. ${ }^{7}$ Thus, understanding nurses' attitudes towards elderly people and attitude towards working with elderly patients are becoming important. $^{8}$

Furthermore, it is found that the quality of care is influenced by the attitudes of health care workers towards elderly people. ${ }^{9}$ This attitude may be affected by personal experiences with elderly people or either the role of education can have a positive or negative influence on nurses' attitudes. ${ }^{10}$ A study conducted in Nigeria showed that nurses had good knowledge on geriatric care though they had negative attitude towards the care of the elderly. The study also identified some of the causes of the poor attitude, and these included poor staffing, difficulty in caring for the elderly and behavioral changes in the elderly. ${ }^{11}$

The quality of care provided for older people was related to attitudes of health care professionals. Negative attitudes towards older people can adversely affect the quality of care provided. Thus, it is important that health personnel need to approach the care of older people with a positive attitude. ${ }^{12}$ If nurses have a poor attitude toward older adults, this can adversely affect the care provided and the ability to staff an aged care workforce. Such concerns will arise in many folds in the coming decades given the current rate of ageing population growth. ${ }^{5}$ Therefore, evaluating nurses' attitude towards aging is essential to increase the number of nurses who desire to work with elderly population. Hence, there is an urgent need to identify the status and factors of attitude of Nepalese nurses towards the care of elderly people. This research proposes to measure the attitude of nurses in providing care to elderly people and its associating factors.

\section{METHODOLOGY}

A cross-sectional research design was used to identify the attitude of nurses towards care of elderly people in teaching hospitals of Kathmandu valley. The study population consisted of 450 nurses who had completed at least six months of work experience and was conducted in eight teaching hospitals (Tribhuvan University Teaching hospital (TUTH), Manmohan Cardio Thoracic Vascular and Transplantation Centre (MCTVT), Kist Medical College and Hospital (KIST), Shree Birendra Hospital (SBH), Nepal Medical College (NMC), Kathmandu Medical College (KMC), National Academy of Medical Science (NAMS), and Patan Academy of Health Sciences (PAHS) of Kathmandu valley which was selected as purposively.

The sample size was calculated by using the formula: $n_{0}=\left[\left(z^{2} p q\right)+M E^{2}\right] /\left[M E^{2}+z^{2} p q / N\right]$, where, $Z=1.96$ for $95 \%$ confidence level, $p=50 \%$ from conventional method, $q=1-p$, ME (Margin of error) $=5 \%, n_{0}=$ Sample Size and $\mathrm{N}=$ Population Size (2136 nurses). The required sample size was 326 nurses for 95\% confidence level. Allowing nonresponse error, the following formula was used: $n^{\prime}=n_{0}+10 \%$ of $n_{0}$. Therefore, the sample was 359 nurses. Thereafter, the precise sample was calculated for maintaining the power of test by using this formula: $\mathrm{N}_{\mathrm{o}}=\mathrm{n}^{\prime} / 0.8$. Finally, the sample size was 449 nurses. The proportionate stratified random sampling technique was used to divide the population into eight strata of teaching hospital. Further calculated sample from strata was selected by using convenience sampling technique. The strata sample size was determined by using following equation ${ }^{13} n_{h}=n / N$, where $n_{h}$ : Sample size for stratum $h, N$ : total population size and $\mathrm{n}$ : Sample Size. Here, sampling fraction is 0.21 . Therefore, the sample size of each was: All the teaching hospital of Kathmandu valley.

The instruments used in this study were composed of two parts. Part I was related to structured questionnaire on socio-demographic and other variables of nurses. Part II consisted of attitude related questionnaires which was adopted standard tool namely, "Multi-factorial Attitudes Questionnaires (MAQ)". The tool was developed by Dr. Angela Kydd (1999) to identify the attitude of nurses towards the care of elderly people. The MAQ included 20 statements. For each statement, participant was required to respond on a five-point Likert scale: $1=$ strongly agree; 2= agree, $3=$ unsure; 4 = disagree; 5 = strongly disagree . Seven of the 20 statements were positive and remaining 13 were negative statements. The negative score was reversed, so that higher score for each statement indicates positive attitude versus a lower score indicates negative attitude. A total MAQ score ranging from 20 to 100 was obtained by adding all the scores from the 20 statements. After completing the Likert scale questionnaire, all the responses were further divided into two categories negative and positive for its analysis purpose. Agree and strongly agree responses were categorized as positive attitude and scored 1 and strongly disagree, disagree and unsure were categorized as negative attitude and scored zero. 
The validity of the instrument was established by reviewing the related literatures and consulting with subject experts. The MAQ was translated into Nepali language following the procedure by Panthee et al. ${ }^{14}$ First, the questionnaire was translated from English into Nepalese by two independent translators and the back-translated by the translators who were unaware of the original items of MAQ. The backtranslated questionnaire was compared to the original English version by the authors. In the evaluation of those two versions, it was found the similar meaning with the original one. Thus, final Nepali version was established and pretested with $10 \%$ of the total sample in similar population before finalizing the instrument. Cronbach's alpha was tested for ensuring internal consistency and 0.70 was acceptable. In this present study the Cronbach alpha was 0.72 .

Written permission was taken from the author for using MAQ. Ethical clearance was taken from Nepal Health Research Council (NHRC), National Academy of Health Sciences (NAMS) and Patan Academy of Health Sciences (PAHS). Data was collected using self-administrative questionnaire in Nepali version from $17^{\text {th }}$ April 2017 to $16^{\text {th }}$ April 2018. The researcher introduced herself and explained the purpose, significance of the study and provided clear instructions about answering the questions to the participants (nurses). Informed written consent was taken from each participant prior to the distribution of questionnaires. The questionnaires were distributed to 450 nurses and filled questionnaire was collected by researcher herself after one week of distribution. The data was checked by the researcher to ensure that the questionnaire was properly done. Anonymity of the respondents was maintained by using code number and not revealing the individual identity in the report findings.

Data cleaning and analysis was done by using Statistical Package of Social Science (SPSS) software version 16. Descriptive statistical methods such as frequency, percentage, mean, and standard deviation was used to assess sociodemographic variables and attitude towards care of older people among nurses of teaching hospitals. Inferential Statistics method such as chi-square test was used at $5 \%$ level of significance to analyze the association between socio-demographic characteristics and attitude of nurses towards care of elderly people in teaching hospitals.

\section{RESULTS}

In this study, the sample consisted of 450 nurses with aged range of $20-59$ years. The majority (62.9\%) of the respondents were between ages of 20-29 years. The mean age of the respondents was 30.04 years with standard deviation of 8.39. Regarding ethnicity, one third (33.1\%) of the respondents was Newar. Likewise, most $(90.4 \%)$ of the respondents were believed in Hindu religion. Regarding marital status, more than half $(58.4 \%)$ of the respondents were married and nearly half $(49.6 \%)$ of the respondents were lived in joint family. Similarly, more than half (58.9\%) of the respondents had an elderly person living with them. Regarding education, majority $(44.2 \%)$ of the respondents had persuaded bachelors' level and nearly two thirds $62.2 \%(n=280)$ had studied geriatrics nursing in different level of their education. Among 280 respondents, 69.3\% ( $n=194)$ had studied geriatric nursing in their bachelor's degree. Among 450 respondents, half (50\%) of the respondents were currently working with elderly people at their workplace. Likewise, more than half $(52 \%)$ of the respondents had more than 5 years of working experience.

Nurses' attitude towards care of elderly people was measured by Multi factorial Attitude Questionnaires (MAQ). The present study showed that more than half (55.3\%) of the respondents (nurses) demonstrated negative attitude towards care of elderly people, whereas less than half $(44.7 \%)$ of the respondents had positive attitude.

Regarding association between socio-demographic characteristics and attitude of nurses towards elderly care, there was significant association between age, marital status, studied geriatric nursing and work experiences in nursing with attitudes of nurses. However, there was no significant association found of ethnicity, religion, type of family, living with elderly people and currently working with elderly with attitudes of nurses.

Table 1: Respondents' Socio-demographic Characteristics: Age, Ethnicity, Religion, Marital Status, Types of family \& Elderly People in Home $\mathrm{N}=450$

Characteristics Frequency Percent

Age in years

$\begin{array}{lcc}20-29 & 283 & 62.9 \\ 30-39 & 106 & 23.6 \\ 40-49 & 32 & 7.1 \\ 50-59 & 29 & 6.4\end{array}$

Mean \pm SD

$30.04 \pm 8.396$

Ethnicity

$\begin{array}{lcc}\text { Newar } & 149 & 33.1 \\ \text { Brahmin } & 142 & 31.6 \\ \text { Chhetri }^{\text {Others }}{ }^{\mathrm{a}} & 112 & 24.9 \\ & 47 & 10.4\end{array}$

Religion

$\begin{array}{lcc}\text { Hindu } & 407 & 90.4 \\ \text { Buddhist }^{\text {Others }}{ }^{\mathrm{s}} & 33 & 7.4 \\ \text { Oth } & 10 & 2.2\end{array}$

Marital status

$\begin{array}{lll}\text { Married } & 263 & 58.4 \\ \text { Unmarried } & 187 & 41.6\end{array}$

Type of Family

Joint family $\quad 223 \quad 49.6$

Nuclear family $\quad 219 \quad 48.7$

Extended family $\quad 8 \quad 1.7$

Elderly people in home

Yes

265

58.9

No

185

Note: ${ }^{a}$ Gurung, Rai, Sherpa, Giri and Madhesi; ${ }^{b}$ Christian, Muslim, 
Table 2: Respondents' Level of Educational, Studied Geriatrics Nursing, Work Experience and Currently Working with Elderly

\begin{tabular}{|c|c|c|c|}
\hline \multicolumn{4}{|c|}{ Level of Education } \\
\hline \multicolumn{2}{|c|}{ PCL Nursing } & 161 & 35.8 \\
\hline \multicolumn{2}{|c|}{ BN/BNS } & 199 & 44.2 \\
\hline \multicolumn{2}{|c|}{ B.Sc. Nursing } & 69 & 15.3 \\
\hline \multirow{2}{*}{\multicolumn{4}{|c|}{$\begin{array}{l}\text { Master's in nursing } \\
\text { Studied geriatrics nursing }\end{array}$}} \\
\hline & & & \\
\hline \multicolumn{2}{|l|}{ Yes } & 280 & 62.2 \\
\hline \multicolumn{4}{|c|}{$\begin{array}{l}\text { No } \\
\text { If yes, in which level }(n=280)\end{array}$} \\
\hline \multicolumn{2}{|c|}{ Certificate } & 39 & 13.9 \\
\hline \multicolumn{2}{|c|}{ Bachelors } & 194 & 69.3 \\
\hline \multicolumn{2}{|c|}{ Masters } & 47 & 16.8 \\
\hline \multicolumn{4}{|c|}{ Working experience in nursing } \\
\hline \multicolumn{2}{|c|}{ Up to 5 years } & 216 & 48.0 \\
\hline \multicolumn{2}{|c|}{ More than 5 years } & 234 & 52.0 \\
\hline \multicolumn{4}{|c|}{ Currently working with elderly } \\
\hline & 225 & 50.0 \\
\hline & 225 & 50.0 \\
\hline \multicolumn{3}{|c|}{ Table 3: Attitude among the Respondents } & $\mathrm{N}=450$ \\
\hline Attitude & Number & \multicolumn{2}{|c|}{ Percent } \\
\hline \multirow{2}{*}{$\begin{array}{l}\text { Positive } \\
\text { Negative }\end{array}$} & 201 & \multicolumn{2}{|c|}{44.7} \\
\hline & 249 & \multicolumn{2}{|c|}{55.3} \\
\hline
\end{tabular}

Table 3 reveals that among the 450 nurses, the respondents 201 (44.7\%) had positive attitude and the number of respondents 249 (55.3\%) had negative attitude towards elderly care.

\begin{tabular}{|c|c|c|c|c|c|c|}
\hline \multirow{3}{*}{$\begin{array}{c}\text { Socio-demographic } \\
\text { Variables }\end{array}$} & \multicolumn{4}{|c|}{ Level of Attitude } & \multirow{3}{*}{$\begin{array}{c}\text { Chi-square } \\
\text { value }\end{array}$} & \multirow{3}{*}{$\begin{array}{c}p \\
\text { value }\end{array}$} \\
\hline & \multicolumn{2}{|c|}{ Negative } & \multicolumn{2}{|c|}{ Positive } & & \\
\hline & $n$ & $\%$ & $\mathrm{n}$ & $\%$ & & \\
\hline \multicolumn{7}{|l|}{ Age } \\
\hline $\begin{array}{l}\text { Young adulthood } \\
\text { Middle adulthood }\end{array}$ & $\begin{array}{c}181 \\
20\end{array}$ & $\begin{array}{l}46.5 \\
32.8\end{array}$ & $\begin{array}{c}208 \\
41\end{array}$ & $\begin{array}{l}53.5 \\
67.2\end{array}$ & 4.029 & 0.045 \\
\hline \multicolumn{7}{|l|}{ Ethnicity } \\
\hline Brahmin/Chhetri & 110 & 43.3 & 144 & 56.7 & \multirow[b]{2}{*}{0.436} & \multirow[b]{2}{*}{0.509} \\
\hline Janajati and Others & 91 & 46.4 & 105 & 53.6 & & \\
\hline \multicolumn{7}{|l|}{ Religion } \\
\hline Hindu & 186 & 45.7 & 221 & 54.3 & \multirow[b]{2}{*}{1.841} & \multirow[b]{2}{*}{0.175} \\
\hline Buddhist and others & 15 & 34.9 & 28 & 65.1 & & \\
\hline \multicolumn{7}{|l|}{ Marital Status } \\
\hline Married & 105 & 39.9 & 158 & 60.1 & \multirow{2}{*}{$5 \cdot 76$} & \multirow{2}{*}{$0.016^{*}$} \\
\hline Unmarried & 96 & 51.3 & 91 & 48.7 & & \\
\hline \multicolumn{7}{|l|}{ Type of Family } \\
\hline Nuclear family & 101 & 46.1 & 118 & 53.9 & \multirow[b]{2}{*}{0.364} & \multirow{2}{*}{0.546} \\
\hline Joint and extended family & 100 & 43.3 & 131 & 56.7 & & \\
\hline \multicolumn{7}{|l|}{ Living with elderly people } \\
\hline Yes & 109 & 41.1 & 156 & 58.9 & \multirow{2}{*}{3.258} & \multirow{2}{*}{0.071} \\
\hline No & 92 & 49.7 & 93 & 50.3 & & \\
\hline \multicolumn{7}{|l|}{ Education } \\
\hline PCL nursing & 78 & 48.4 & 83 & 51.6 & \multirow{2}{*}{1.45} & \multirow{2}{*}{0.229} \\
\hline Bachelors and others & 123 & 42.6 & 166 & 57.4 & & \\
\hline \multicolumn{7}{|l|}{ Studied geriatrics nursing } \\
\hline Yes & 112 & 40.0 & 168 & 60.0 & \multirow{2}{*}{6.531} & \multirow{2}{*}{$0.011^{*}$} \\
\hline No & 89 & 52.4 & 81 & 47.6 & & \\
\hline Work experiences in nursi & & & & & & \\
\hline $0-5$ years & 110 & 50.7 & 107 & 49.3 & 6.155 & $0.013^{*}$ \\
\hline above 5 years & 91 & 39.1 & 142 & 60.9 & & \\
\hline Currently working withelderl & & & & & & \\
\hline Yes & 103 & 45.8 & 122 & 54.2 & & \\
\hline No & 96 & 43.6 & 127 & 56.4 & 0.225 & 0.635 \\
\hline
\end{tabular}

Note: * Significant at $5 \%$ level of significance

\section{DISCUSSION}

This study aimed to identify the attitude of nurses towards care of elderly people in Teaching hospital of Kathmandu valley. Nurses' attitude towards care of elderly people was measured by Multi factorial Attitude Questionnaires (MAQ). The present study revealed that among 450 nurses more than half $(55.3 \%)$ of the respondents had negative attitude towards care of elderly people. This study finding is slightly higher compared with study done in Chitwan Medical College (CMC), Nepal ${ }^{15}$ that revealed nearly half $(49.7 \%)$ of the nurses had positive attitudes, by using Kogan's tool to measure attitude towards elderly.

Although the eastern society has the tradition of caring their dependent elderly family members, which is being handed over the generations, there is huge respect in caring the elderly people. However, as the society is being more westernized day by day younger generations are being busier in their lives; lacking the concern for their elderly which affected their attitude towards the elderly people. Another supportive finding was obtained in a study done in Iran $^{16}$ which revealed more than half $(54.3 \%)$ nurses had negative attitude towards elderly. The contrast finding was suggested by the study done in Saudi Arabia ${ }^{17}$ among 300 nurses, which revealed that only $5 \%$ of nurses had negative attitude whereas rest had neutral (30\%) and positive attitude (65\%). The study rationalises the finding as a cause that majority of nurses were female who are culturally pivotal in taking care of every member of family including elderly in Arabian countries. This result might be due to the marital status of the respondents as more than half of them were married. They had to take their professional as well as personal life together which might had created such attitude towards the elderly, as they are hard to look after and need more patience. High level of commitment must be required for caring the elderly with positive attitude.

This study showed that there was significant association between age, marital status, studied geriatric nursing and work experiences in nursing with attitudes of nurses towards care of elderly. Previous literature stated nursing curriculum has an important role in either cultivating or changing to positive toward elderly people and affecting their work choice. ${ }^{17}$ This study also revealed that the nurses who studied geriatric nursing in their curriculum had significant positive attitude $\left(\chi^{2}=6.531, p=0.011\right)$ than the nurses who did not study geriatric nursing course in their curriculum. Similar findings were revealed by the study done in Saudi $\mathrm{Arabia}^{17}$ which shows that there was positive relationship between studied geriatric course and attitude of nurses ( $r=.137, p=.017)$ and no association was noted with other variables. This study finding shows similar result with a study conducted among 230 nurses of public hospital of $\operatorname{Iran}^{16}$ displayed significant mean difference $(t=1.94, p$ value $<0.04)$ between age, marital status, work experience and ward type and attitude towards elderly. However, in a study conducted in Chitwan Medical College (CMC), Nepal ${ }^{15}$ has shown no association between any socio-demographic variables and attitude. Likewise, a study regarding perception knowledge and attitude of nursing students of Nigeria ${ }^{19}$ has revealed no statistically significant association with attitude towards care of elderly. The present study also revealed that the nurses who had studied geriatric nursing course in their curriculum had positive attitude towards elderly people. 
It has been recommended that quality care of the elderly needs some special geriatric nursing course-based training, adequate staffing with some work experience to reduce stress and improve quality of care. There is need for conducting education on geriatric nursing to quality nursing practice in the care of elderly. If nurses are provided with the related education, they can deliver quality of care and develop positive attitudes in caring for elderly people in their professional practice. ${ }^{20}$ Thus, positive attitude is important to provide quality care to the elderly and for it the education plays an important role.

\section{CONCLUSION}

Based on the findings of the study, it is concluded that more than half of the respondents had negative attitude towards the care of elderly people. Gerontological nursing plays important role in early formation of attitude towards care of elderly. Similarly, the registered nurses also act as the clinical role models for the student nurses whose attitude towards elderly care must also be given priority as they could also shape the attitude of the next generation of nurses.

\section{RECOMMENDATIONS}

Based on the findings of the study, following recommendations are made: The study should be replicated to larger sample and in different setting to generalize the findings. And there is a need to conduct a comparative study between the nurses who had studied geriatric nursing in their curriculum and who did not have studied geriatric nursing in their curriculum. Refreshing course/Training/workshops should be conducted periodically for nurses to increase awareness in importance of nurses' role in providing quality care to the elderly. Further qualitative study can be done to explore the factors affecting the attitudes of the nurses in elderly care.

\section{LIMITATION OF THESTUDY}

The study used convenience sampling technique so sample bias may occur. Similarly, the study was conducted by using self-administered questionnaire and respondents had one week to respond the questionnaire thus the study may have chance to communicate with each other to respond the questionnaires there might be response bias.

\section{ACKNOWLEDGEMENT}

We express our thanks to Dr. Angela Kydd for providing us the Multifacorial Attitude Questionnaires tool to use in this study. We would like to express our sincere thanks to authorities of different teaching hospitals for granting permission to carry out this study. Similarly, we would like to express our sincere thanks to Manju Maharjan for necessary help in statistical analysis and interpretation and Amita Maharjan for data entry and necessary support. Finally, we would like to thank you all the respondents for their exceptional effort and cooperation by giving their valuable time to participate in this study.

\section{FINANCIAL DISCLOSURE}

This study was funded by University Grant Commission (UGC), Sanothimi, Bhaktapur, Nepal under the Faculty Research Development and Innovation Grant and research team of UGC supervised our work throughout the research process.

\section{CONFLICT OFINTEREST}

There was no any conflict of interest to declare.

11. Oyetunde MO, Ojo OO, Ojewale LY. Nurses' attitude towards the care of the elderly: Implications for gerontological nursing training. Journal of Nursing Education and Practice. 2013 Jul 1;3(7):150. DOI:10.5430/jnep.v3n7p150

12. Hweidi IM, Al-Obeisat SM. Jordanian nursing students' attitudes toward the elderly. NurseEeducationToday. 2006 Jan 1;26(1):2330.DOI:10.1016/j.nedt.2005.06.003

13. Panta PP. A textbook of biostatistics. 2nded. Kathmandu: Alliance Printers \& Media House Pvt.Ltd;2016

14. Panthee B, Panthee S, Shimazu A, Kawakami N. Validation of the Nepalese version of Recovery Experience Questionnaire. Heliyon. $2020 \mathrm{Apr}$ 1;6(4):DOI 10.1016/j.heliyon.2020.e03645

15. Subba HK. Subba R, Poudyal S. Attitudes towards older patients among nurses working In hospital. Journal of Nursing and Health Science. 2019 Sep-Oct;8(5):31-35 DOI:10.9790/1959-0805043135

16. Arani MM, Aazami S, Azami M, Borji M. Assessing attitudes toward elderly among nurses working in the city of llam. International Journal of Nursing Sciences. 2017 Jul 10;4(3):311-3. DOI: 10.1016/j.ijnss.2017.06.009

17. Elebiary $\mathrm{H}$, Elshenewy $\mathrm{H}$, Abulaxm, $\mathrm{S}$. Knowledge and attitudes of nurses toward caring of elderly people in health care sittings. Journal of Nursing and Health Science. 2018 Nay-June;7(3):76-84.DOI:109790/19590703057684

18. King BJ, Roberts TJ, Bowers BJ. Nursing student attitudes toward and preferences for working with older adults. Gerontology \& Geriatrics Education $2013 \mathrm{Jul}$ 1;34(3):272-291. DOI:10.1080/ 02701960. 2012.718012

19. Faronbi JO, Adebowale O, Faronbi GO, Musa OO, Ayamolowo SJ. Perception knowledge and attitude of nursing students towards the care of older patients. International Journal of Africa Nursing Sciences. 2017 Jan 1;73742. DOI:10.1016/j.ijans.2017.06.004

20. Baumbusch J, Dahlke S, Phinney A. Nursing students' knowledge and beliefs about care of older adults in shifting context of nursing education. Journal of Advance Nursing. 2012 Nov;68(11):2550-8. DOI:10.1111/j.13652648.2012.05958

10. Henderson J, Xiao L, Siegloff L, Kelton M, Paterson J. 'Older people have lived their lives': First year nursing students' attitudes towards older people. Contemporary Nurse. 2008Aug 1;30(1):32-45.DOI:10.5172/conu.673.30.1.32 